\title{
The Nuclear Transport Protein Importin-5: A Promising Target in Oncology and Virology
}

\author{
Rémi Patouret* \\ SCS-DSM award for best virtual poster in Medicinal Chemistry
}

\begin{abstract}
Cellular homeostasis importantly relies on the correct nucleoplasmic distribution of a large number of RNA molecules and proteins, which are shuttled by specialized transport receptors. The nuclear import receptor importin-5, also called IPO5, RanBP5 or karyopherin $\beta 3$, mediates the translocation of proteins to the nucleus, and thus regulates critical signaling pathways and cellular functions. The normal function of IPO5 appears to be disrupted in cancer cells due to aberrant overexpression. IPO5 also demonstrated a pivotal role in viral replication. The constant increasing number of publications shows an interest within the scientific community as a therapeutic target due to its pivotal role in protein trafficking.
\end{abstract}

Keywords: Importin-5 $\cdot$ IPO5 $\cdot$ Nuclear transport

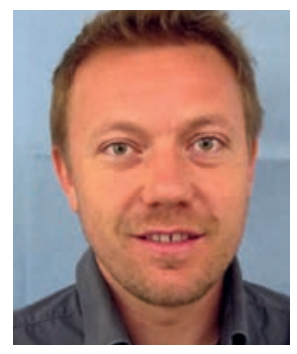

Rémi Patouret was born in Burgundy, France. During his MSc studies in organic synthesis at University of Nantes, he cumulated various experiences in chemistry at CNRS Gif-sur-Yvette and in a spin-off of Aventis under the supervision of Dr. Deprez. He worked 3 years at INSERM with Prof. Roques in the preclinical development of Firibastat, a first-in-class APA inhibitor, and 3 years at Pharmaleads to work in the field of dual metalloprotease inhibitors. After 1 year at Strasbourg University with Dr. Rognan (FLT3 inhibitors discovery) and 2 years at SCRIPPS Florida with Dr. Kamenecka to develop RORs nuclear receptor modulators, he joined in 2016 the group of Prof. Winssinger for a $\mathrm{PhD}$ at the University of Geneva, where his research focuses on the total synthesis of natural products and target identification.

\section{Introduction}

In 1997, a $124 \mathrm{kDa}$ protein was identified and characterized as a novel Ran binding protein and named RanBP5.[1] This protein is related to importin $\beta$ family, which is a part of the karyopherin superfamily.[2] Thus, RanBP5 can be called IPO5, importin-5, importin $\beta-3$, karyopherin $\beta 3$ or KPNB3. In these initial reports, IPO5/RanBP5 (hereafter referred to as IPO5) was found to bind short amino acid sequences called nuclear localization sequences (NLSs) in proteins that were actively imported to the nucleus from the cytosol. IPO5 has been shown to mediate the nuclear import of not only cellular proteins, but also viral proteins. ${ }^{[3]}$ In fact, crucial signaling pathways, such as RAS pathway and viral replication processes, involve IPO5-dependent nuclear import steps. ${ }^{[4]}$ The constant increasing number of publications (Fig. 1) demonstrates an interest as a therapeutic target due its crucial role in protein trafficking.

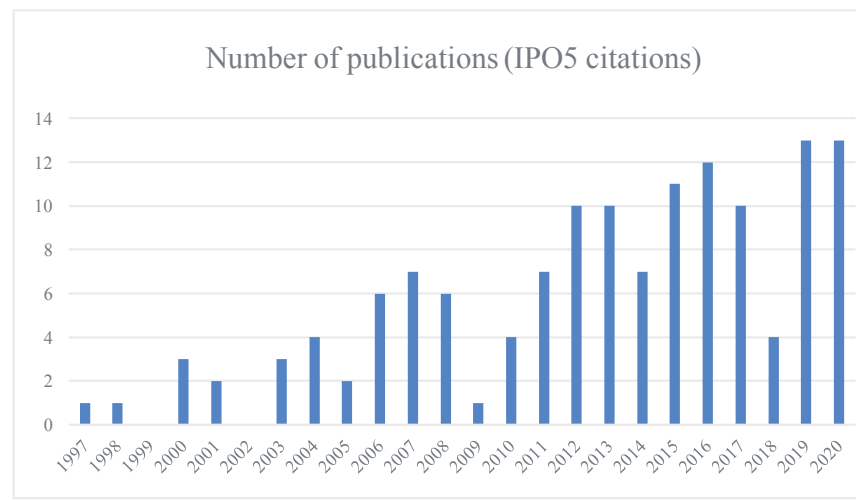

Fig. 1. Number of publications per year in which IPO5 is mentioned.

\section{The Biological/Physiological Roles of IPO5}

\subsection{Overview of Nucleocytoplasmic Transport of Proteins}

The nuclear envelope, in eukaryotic cells, provides a physical separation between the nucleus and the cytoplasm. Continuous communication is required between these compartments through the bidirectional trafficking of molecules. ${ }^{[5]}$ While these transportations occur by diffusion in the case of small molecules, the vast majority of proteins can only enter and exit the nucleus through nuclear pore complexes (NPCs). ${ }^{[6]}$ Nucleocytoplasmic transport is an active process and, for most proteins, requires three crucial components: a family of transportin receptors that recognize and bind specific transport signals in the cargo proteins; the NPCs; a gradient of the small GTPase Ran (GTP or GDP) across the nuclear envelope, which confers directionality to the transport. ${ }^{[7]}$ 
NPCs are large complexes formed by the assembly of approximately 30 different proteins called nucleoporins (NUPs). NUPs, in the inner channel of the pore, contain disordered domains rich in phenylalanine-glycine (FG) repeats. These so-called FGnucleoporins are a barrier that prevents proteins above a certain size from freely diffusing across the NPC. ${ }^{[8]}$ Large proteins (and even very large nucleoprotein complexes) can overcome the selective barrier of the NPC through binding to karyopherins. ${ }^{[9]}$

The human genome codes for more than twenty different transportins/karyopherins. ${ }^{[10]}$ While some of these receptors can mediate bidirectional transport of cargos, most of them function exclusively as either export receptors (exportins) or import receptors (importins), such as IPO5. Karyopherins can recognize and bind specific peptide sequences in the cargo protein, and can be broadly classified as nuclear localization signals (NLSs, recognized by importins) or nuclear export signals (NESs, recognized by exportins). ${ }^{[11]}$ Members of importin $\beta$ typically bind to adapter proteins importin $\beta$, which are responsible for binding to NLScontaining cargo. ${ }^{[12]}$ In the case of IPO5, it can bind cargos directly without the involvement of an adapter. It is interesting to note that some proteins bear both NLS and NES and can undergo cyclic shuttling between the nucleus and the cytosol.

The direction of its transport is defined by the binding and release of a protein in the cytosol or the nucleus. The key factor that regulates cargo binding and release is the GTPase Ran, which can be bound to either GDP (RanGDP) or GTP (RanGTP), depending on the gradient across the nuclear envelope. ${ }^{[7 a, 13]}$ This gradient is maintained by the Ran cofactors RanGAP1 (a cytoplasmic GTPase activating protein) and RCC1 (a chromatinbound nucleotide exchange factor). In the case of IPO5 (Fig. 2), RanGTP promotes disassembly of the IPO5/cargo complex, leading to release of import cargo in the nucleus. The complex IPO5/ RanGTP is disassembled upon GTP hydrolysis in the cytosolic side of the NPC.

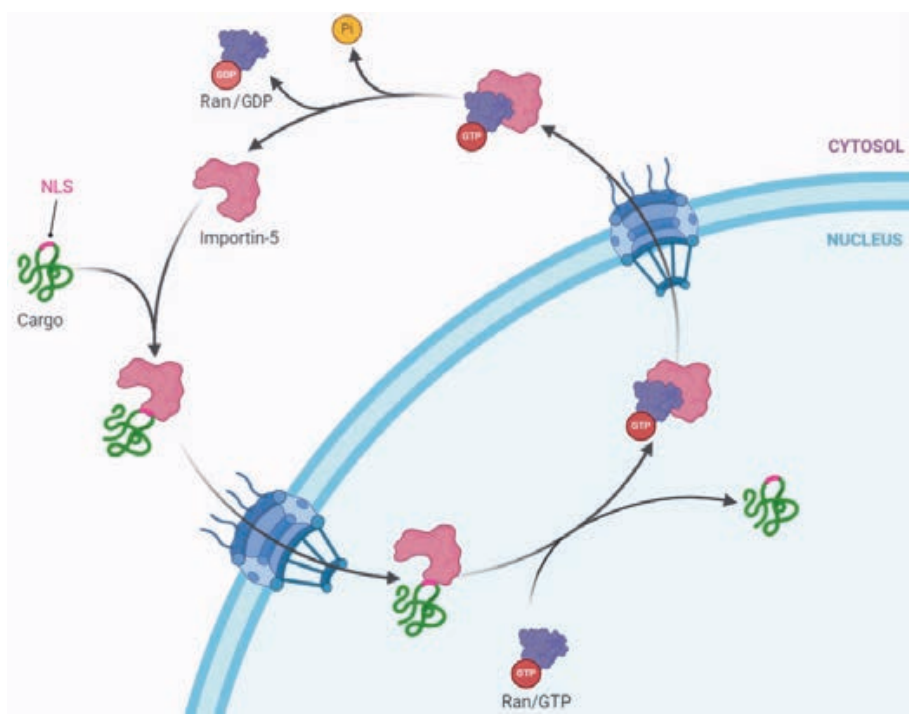

Fig. 2. Illustrative overview of the IPO5 nuclear import. Nuclear import of a cargo protein bearing a NLS mediated by IPO5. Adapted from 'TRPS1 Transport into the nucleus', by BioRender.com (2021). Retrieved from https://app.biorender.com/biorender-templates

\subsection{IPO5-mediated Protein Nuclear Import. Cargos, Mechanisms and Roles}

A dozen characterized cargos has been identified for IPO5 so far, including not only cellular proteins, but also viral proteins. Identification of IPO5 cargos remains a challenge as IPO5 has still no identified modulator. While we will develop IPO5 altera- tion in cancer and its role in virology, it has been shown that IPO5 translocate various cargos in which the implication remains to be defined. IPO5 facilitates nuclear import of ribosomal proteins in an in vitro translocation assay system. ${ }^{[14]}$ It has also been reported to translocate $\mathrm{p} 35$, a Cdk5 activator which plays a pivotal role in a multitude of nervous system activities ranging from neuronal differentiation to degeneration. ${ }^{[15]}$ IPO5 also physically interacts with apoliprotein A-1 (apo A-1) and FLIL33.[16]

\subsection{Alteration of IPO5 in Cancer}

Normal cell function relies on the correct subcellular proteins distribution of thousands of proteins. The presence of a critical protein in the wrong cellular compartment may have severe pathological consequences. ${ }^{[17]}$ For instance, aberrant cytoplasmic localization of a physiologically nuclear tumor suppressor protein may inactivate this protein, and thus contribute to tumorogenesis. In fact, mislocalization of cancer-related proteins has often been demonstrated in human tumors.

Canonical Wnt pathway activity is involved in the development of benign and malignant various cancer. ${ }^{[18]}$ Nuclear translocation of $\beta$-catenin is a key step in canonical Wnt signaling. ${ }^{[19]}$ Goto et al. has observed that IPO5 interacts with IQGAP1, a regulator of $\beta$-catenin, and depletion of IPO5 reduced expression of Wnt target genes during early embryogenesis. ${ }^{[20]}$ Zhang et al. observed that IPO5 was highly expressed and positively correlated with the clinicopathological characteristics of colorectal cancer $(\mathrm{CRC})$ tissues. ${ }^{[4 \mathrm{c}]}$ Functional experiments indicated that IPO5 could promote the development of CRC. They screened RASAL2, one cargo of IPO5, and confirmed that IPO5 bound to the NLS sequence of RASAL2, mediating nuclear translocation and inducing RAS signal activation, thereby promoting the progression of CRC. These results indicate that IPO5 is an oncogene and may play a crucial role in CRC. It is known that c-Jun plays a role in cellular proliferation and was the first oncogenic transcription factor discovered.[21] Waldmann et al. indicated that IPO5 and IPO13 specifically interact with c-Jun and demonstrated the high level of promiscuity of c-Jun with respect to nuclear import receptors. ${ }^{[22]}$ More recently, Li et al. observed that IPO5 expression in tumor tissues of oesophageal cancer patients was significantly higher than in adjacent normal ones. ${ }^{[4 b]}$ Compared with control group, the proliferation ability of oesophageal cancer cells in IPO5 knockdown group was significantly decreased. Dual luciferase reporter assay results suggested that IPO5 specifically binds MMP7 and propose that IPO5 may promote tumor progression of oesophageal cancer through MMP7 regulation.

These investigations show that IPO5 is expected to be a promising oncologic target.

\subsection{Role of IPO5 in Virology}

Viruses have been significant tools for discovering key pathways of nucleocytoplasmic transport. ${ }^{[23]}$ Also, because the entrance and exit of molecules are controlled by the nuclear transport machinery with key biological functions, targeting of several nuclear transport pathways has been shown to be crucial for the viruses' life cycle.

Influenza A must import several polymerase proteins to replicate, and Deng et al. showed that IPO5 interacts with the viral protein PB1 and the heterodimer PA-PB1.[4a] They also observed that a knockdown of IPO5 inhibits the nuclear accumulation of the PA-PB1 dimer. In 2011, Hutchinson et al. characterized and located the binding site in the N-terminal aa of PB1 and demonstrated that mutating the binding site reduced the ability of PB1 to localize to the nucleus. ${ }^{[3 b]}$ Moreover, Swale et al. demonstrated that the viral heterodimer PA-PB1 forms a stable and stoichiometric complex with IPO5.[24] In 2019, Mohl et al. designed the first inhibitors targeting PB1 to disrupt interaction with IPO5.[25] Their results suggests that their compound destabilizes the viral 
PB1-PA heterodimer interaction or the PB1-PA-IPO5 heterotrimer. Another prominent example of IPO5 viral cargo is the Rev protein of the human immunodeficiency virus type 1 (HIV-1). HIV Rev is a shuttling protein that is required for nuclear export of unspliced viral mRNAs. ${ }^{[26]}$ Arnold et al. demonstrated that IPO5 interacts with HIV-Rev by pulldown of IPO5 with immobilized GST-Rev. ${ }^{[3 a]}$ In 2014, Levin et al. synthesized the NLS sequence of HIV-Rev and observed a binding with IPO5 in a nanomolar range. ${ }^{[27]}$ The same research group showed interactions between hepatitis $\mathrm{C}$ virus (HCV) viral NLSs of Core, NS3, NS5A and IPO5. Finally, IPO5 is one of the importins recruited by the high risk human papillomavirus type 16 (HPV16). ${ }^{[28]}$ Darshan et al. showed that the viral L2 protein of HPV16 interacts with IPO5 to form a complex, and deletion of the principal NLS of L2 protein disrupts the interaction and the transport with IPO5. ${ }^{[29]}$ In 2008, Krawczyk et al. identified the oncoprotein 16E5 of HPV16 as a cargo of IPO5 and demonstrated that the interaction is primarily mediated by 10 amino acids at the C-terminus of 16E5, since the deletion mutant is largely defective for binding to IPO5.[3c]

Collectively, all these investigations show that IPO5 plays a significant role in infectious disease.

\section{Conclusion}

After its identification as a receptor that mediates the nuclear import of proteins, there is multiple evidence that IPO5 represents a promising target in cancer and in virology. To the best of our knowledge, there is still no modulator described in the scientific literature and thus, further development has suffered. Only few examples of small molecules are described to modulate protein trafficking within the cell. One example is leptomycin (Fig. 3), through covalent modification of Cys529 of exportin-1 (XPO1), a protein which transport cargos from the nucleus to the cytosol. [30] Significant efforts in medicinal chemistry led to the development of Selinexor, a covalent inhibitor which is FDA approved for multiple myeloma and diffuse large B-cell lymphoma. Several examples described the crucial role of IPO5 and a significant biological effect when silencing IPO5. For instance, subcutaneous injection of RKO-shNC cells versus RKO-shIPO5 into nude mice showed that IPO5 down-regulation dramatically reduced the tumor volume and points the potential clinical significance of IPO5 in CRC. ${ }^{[4 c]}$

Very recently, the X-ray structure of two distinct isoforms of IPO5 has been described and revealed important new insight in the structure, mechanism and dynamics of IPO5.[31] In conclusion, the discovery of IPO5 inhibitors is highly needed to facilitate investigations and evaluate the therapeutic impact by modulating IPO5 transport cargo trafficking.
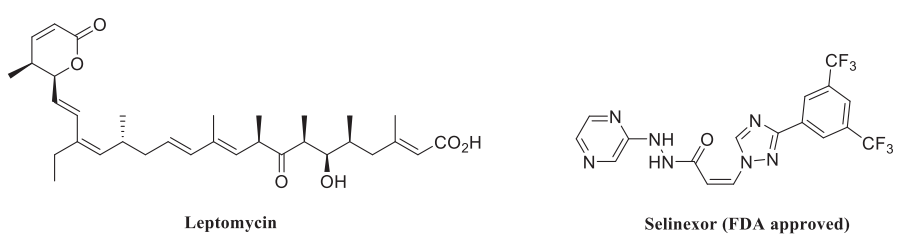

Fig. 3. Structures of leptomycin and selinexor.

\section{Acknowledgements}

Rémi Patouret is grateful to the Swiss Chemical Society and DSM for the best poster presentation award in Medicinal Chemistry. This article is based on the article published in Cancer Drug Resistance by Maria Sendino, Miren Josu Omaetxebarria and Jose Antonio Rodriguez. ${ }^{[32]}$

Received: February 4, 2021
[1] R. Deane, W. Schafer, H. P. Zimmermann, L. Mueller, D. Gorlich, S. Prehn, H. Ponstingl, F. R. Bischoff, Mol. Cell Biol. 1997, 17, 5087, https://doi.org/10.1128/mcb.17.9.5087.

[2] A. C. Strom, K. Weis, Genome Biol. 2001, 2, REVIEWS3008, https://doi.org/10.1186/gb-2001-2-6-reviews3008.

[3] a) M. Arnold, A. Nath, J. Hauber, R. H. Kehlenbach, J. Biol. Chem. 2006, 281, 20883, https://doi.org/10.1074/jbc.M602189200; b) E. C. Hutchinson, O. E. Orr, S. Man Liu, O. G. Engelhardt, E. Fodor, J. Gen. Virol. 2011 92, 1859, https://doi.org/10.1099/vir.0.032813-0; c) E. Krawczyk, J. A Hanover, R. Schlegel, F. A. Suprynowicz, Biochem. Biophys. Res. Commun. 2008, 371, 684, https://doi.org/10.1016/j.bbrc.2008.04.122.

[4] a) T. Deng, O. G. Engelhardt, B. Thomas, A. V. Akoulitchev, G. G. Brownlee, E. Fodor, J. Virol. 2006, 80, 11911, https://doi.org/10.1128/JVI.01565-06; b) X. F. Li, A. L. Aierken, L. Shen, Eur. Rev. Med. Pharmacol. Sci. 2020, 24, 4246, https://doi.org/10.26355/eurrev_202004_21004; c) W. Zhang, Y. Lu, X. Li, J. Zhang, W. Lin, W. Zhang, L. Żheng, X. Li, J. Exp. Clin. Cancer Res. 2019, 38, 296, https://doi.org/10.1186/s13046-019-1290-0.

[5] Y. H. Kim, M. E. Han, S. O. Oh, Anat. Cell Biol. 2017, 50, 77, https://doi.org/10.5115/acb.2017.50.2.77.

[6] K. E. Knockenhauer, T. U. Schwartz, Cell 2016, 164, 1162, https://doi.org/10.1016/j.cell.2016.01.034.

[7] a) B. Cautain, R. Hill, N. de Pedro, W. Link, FEBS J. 2015, 282, 445, https://doi.org/10.1111/febs.13163; b) L. F. Pemberton, B. M. Paschal, Traffic 2005, 6, 187, https://doi.org/10.1111/j.1600-0854.2005.00270.x.

[8] B. L. Timney, B. Raveh, R. Mironska, J. M. Trivedi, S. J. Kim, D. Russel, S. R. Wente, A. Sali, M. P. Rout, J. Cell Biol. 2016, 215, 57, https://doi.org/10.1083/jcb.201601004.

[9] M. Beck, E. Hurt, Nat. Rev. Mol. Cell Biol. 2017, 18, 73, https://doi.org/10.1038/nrm.2016.147.

[10] T. Cagatay, Y. M. Chook, Curr. Opin. Cell Biol. 2018, 52, 30, https://doi.org/10.1016/j.ceb.2018.01.006.

[11] M. Gama-Carvalho, M. Carmo-Fonseca, FEBS Lett. 2001, 498, 157, https://doi.org/10.1016/s0014-5793(01)02487-5.

[12] K. Lott, G. Cingolani, Biochim. Biophys. Acta 2011, 1813, 1578, https://doi.org/10.1016/j.bbamcr.2010.10.012.

[13] a) M. Floer, G. Blobel, M. Rexach, J. Biol. Chem. 1997, 272, 19538, https://doi.org/10.1074/jbc.272.31.19538; b) F. Melchior, B. Paschal, J. Evans, L. Gerace, J. Cell Biol. 1993, 123, 1649, https://doi.org/10.1083/jcb.123.6.1649; cM. S. Moore, G. Blobel, Nature 1993, 365, 661, https://doi.org/10.1038/365661a0.

[14] S. Jakel, D. Gorlich, EMBO J. 1998, 17, 4491, https://doi.org/10.1093/emboj/17.15.4491.

[15] X. Fu, Y. K. Choi, D. Qu, Y. Yu, N. S. Cheung, R. Z. Qi, J. Biol. Chem. 2006, 281, 39014, https://doi.org/10.1074/jbc.M512663200.

[16] a) K. M. Chung, S. S. Cha, S. K. Jang, Mol. Cells 2008, 26, 291; b) A. Clerman, Z. Noor, R. Fishelevich, V. Lockatell, B. S. Hampton, N. G. Shah, M. V. Salcedo, N. W. Todd, S. P. Atamas, I. G. Luzina, J. Biol. Chem. 2017, 292, 21653, https://doi.org/10.1074/jbc.M117.807636; cD. Li, S. Fu, Z. Wu, W. Yang, Y. Ru, H. Shu, X. Liu, H. Zheng, J. Cell Sci. 2020, 133, https://doi.org/10.1242/jcs.244681.

[17] A. Mahipal, M. Malafa, Pharmacol. Ther. 2016, 164, 135, https://doi.org/10.1016/j.pharmthera.2016.03.020.

[18] R. Nusse, Cell Res. 2005, 15, 28, https://doi.org/10.1038/sj.cr.7290260.

[19] a) M. Bienz, H. Clevers, Cell 2000, 103, 311, https://doi.org/10.1016/s0092-8674(00)00122-7; b) B. M. Gumbiner, Curr. Biol. 1997, 7, R443, https://doi.org/10.1016/s0960-9822(06)00214-4.

[20] T. Goto, A. Sato, S. Adachi, S. Iemura, T. Natsume, H. Shibuya, J. Biol. Chem. 2013, 288, 36351, https://doi.org/10.1074/jbc.M113.520528.

[21] a) P. K. Vogt, Nat. Rev. Cancer 2002, 2, 465, https://doi.org/10.1038/nrc818; b) A. Brennan, J. T. Leech, N. M. Kad, J. M. Mason, J. Exp. Clin. Cancer Res. 2020, 39, 184, https://doi.org/10.1186/s13046-020-01686-9.

[22] I. Waldmann, S. Walde, R. H. Kehlenbach, J. Biol. Chem. 2007, 282, 27685 , https://doi.org/10.1074/jbc.M703301200.

[23] B. M. Fontoura, P. A. Faria, D. R. Nussenzveig, IUBMB Life 2005, 57, 65, https://doi.org/10.1080/15216540500078608.

[24] C. Swale, A. Monod, L. Tengo, A. Labaronne, F. Garzoni, J. M. Bourhis, S. Cusack, G. Schoehn, I. Berger, R. W. Ruigrok, T. Crepin, Sci. Rep. 2016, 6, 24727, https://doi.org/10.1038/srep24727.

[25] G. Mohl, N. Liddle, J. Nygaard, A. Dorius, N. Lyons, J. Hodek, J. Weber, D. J. Michaelis, D. D. Busath, Antiviral Res. 2019, 164, 81, https://doi.org/10.1016/j.antiviral.2019.02.003.

[26] L. Gu, T. Tsuji, M. A. Jarboui, G. P. Yeo, N. Sheehy, W. W. Hall, V. W. Gautier, Retrovirology 2011, 8, 17, https://doi.org/10.1186/1742-4690-8-17.

[27] A. Levin, C. J. Neufeldt, D. Pang, K. Wilson, D. Loewen-Dobler, M. A. Joyce, R. W. Wozniak, D. L. Tyrrell, PLoS One 2014, 9, e114629, https://doi.org/10.1371/journal.pone.0114629.

[28] L. M. Nelson, R. C. Rose, J. Moroianu, Virology 2003, 306, 162, https://doi.org/10.1016/s0042-6822(02)00025-9.

[29] M. S. Darshan, J. Lucchi, E. Harding, J. Moroianu, J. Virol. 2004, 78, 12179 , https://doi.org/10.1128/JVI.78.22.12179-12188.2004.

[30] a) N. Kudo, N. Matsumori, H. Taoka, D. Fujiwara, E. P. Schreiner, B. Wolff, 
M. Yoshida, S. Horinouchi, Proc. Natl Acad. Sci. USA 1999, 96, 9112, https://doi.org/10.1073/pnas.96.16.9112; b) B. Nachmias, A. D. Schimmer, Leukemia 2020, 34, 2875, https://doi.org/10.1038/s41375-020-0958-y.

[31] C. Swale, B. Da Costa, L. Sedano, F. Garzoni, A. A. McCarthy, I. Berger, C. Bieniossek, R. W. H. Ruigrok, B. Delmas, T. Crepin, J. Mol. Biol. 2020, 432, 3353, https://doi.org/10.1016/j.jmb.2020.03.021.

[32] M. Sendino, M. J. Omaetxebarria, J. A. Rodríguez, Cancer Drug Resis. 2018, 1, 139, https://doi.org/10.20517/cdr.2018.09.

\section{License and Terms}

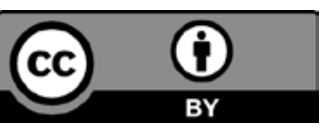

This is an Open Access article under the terms of the Creative Commons Attribution License CC BY 4.0. The material may not be used for commercial purposes.

The license is subject to the CHIMIA terms and conditions: (http:// chimia.ch/component/sppagebuilder/?view=page\&id=12).

The definitive version of this article is the electronic one that can be found at https://doi.org/10.2533/chimia.2021.319 